\title{
AC 2009-1304: DOES MAJOR MATTER? A LOOK AT WHAT MOTIVATES ENGINEERING STUDENTS IN DIFFERENT MAJORS
}

\section{Sarah Parikh, Stanford University}

Sarah Parikh is a third year graduate student at Stanford University working on her $\mathrm{PhD}$ in mechanical engineering with a focus on engineering education. She received a BS in mechanical engineering from the University of Texas at Austin in 2006 and received a MS in mechanical engineering with a focus on microscale heat transfer from Stanford University in 2008.

\section{Helen Chen, Stanford University}

Helen L. Chen is Research Scientist at the Stanford Center for Innovations in Learning and Research Associate in the Center for the Advancement of Engineering Education. Her current research interests focus on the application of ePortfolio pedagogy and practices to facilitate teaching, learning, and assessment for students, faculty, and institutions. She is also interested in the exploration of the affordances and scalability of these kinds of social software tools and their implications for the design and evaluation of innovative learning spaces to support formal and informal learning.

\section{Krista Donaldson, Stanford University}

Krista Donaldson is a researcher and lecturer at Stanford University. Her interests include design and development, reconstruction and engineering education. She received her $\mathrm{PhD}$ from Stanford in mechanical engineering and design where her work focused on product development to promote economic growth in less industrialized economies. Krista has taught at Kenyatta University and the University of Cape Town, and worked as an engineer and designer in a variety of capacities. She is the author of the Engineering Student Survival Guide.

\section{Sheri Sheppard, Stanford University}

Sheri D. Sheppard is the Burton J. and Deedee McMurtry University Fellow in Undergraduate Education, associate vice provost for graduate education, and professor of mechanical engineering at Stanford University. She is also a consulting senior scholar at the Carnegie Foundation, having directed the Preparations for the Professions Program (PPP) engineering study, and co-authored the study's report Educating Engineers: Designing for the Future of the Field (2008). Before coming to Stanford University, she held several positions in the automotive industry, including senior research engineer at Ford Motor Company's Scientific Research Lab. She earned a Ph.D. at the University of Michigan. 


\title{
Does Major Matter? \\ A Look at what Motivates \\ Engineering Students in Different Majors
}

\begin{abstract}
We have found that students' engineering major does matter when looking at what motivates them to study engineering. This may lead to support programs that are better tailored to the students they serve. In addition, these findings may be important in shaping engineering curricula to attract and retain students of different majors.

Using data from the Academic Pathways of People Learning Engineering Survey (APPLES), a national survey of 21 institutions aimed at identifying and characterizing undergraduate students' motivations to study engineering. Using demographic information about engineering major, year in school, and gender, we have determined there are statistically significant differences in the motivational factors between women and men and between students of different majors. The six engineering majors that we compared include: mechanical, electrical, chemical, industrial, aerospace and bioX (a compilation of biology-related majors).

Using t-tests and analysis of variance tests (ANOVAs), the trends across majors and gender for intrinsic psychological motivation, intrinsic behavioral motivation, social good motivation, financial motivation, mentor influence motivation, and parental motivation to study engineering were explored.

Our findings show that there are significant differences in the level of motivation for students of different engineering majors. For men, the level of intrinsic behavioral motivation to study engineering is significantly lower for industrial engineering students than for mechanical or aerospace engineering students. For women, the levels of intrinsic behavioral, intrinsic psychological, and financial motivation vary greatly according to engineering major. These findings suggest treating these groups individually when considering motivational factors of undergraduate engineering students.
\end{abstract}

\section{Introduction}

In this paper a comparative analysis of motivational factors by engineering major is presented to shed light on how various dimensions of the undergraduate engineering experience may be different for students in different majors.

We are interested in looking at motivation for several reasons. The goals of the NSF-funded Center for the Advancement of Engineering Education (CAEE) were to "identify ways to boost the numbers of students who complete engineering degrees (including increasing the numbers of women and traditionally underrepresented groups)" and to "better support those enrolled in engineering programs" ${ }^{, 1,2}$ Identifying similarities and differences between groups of engineering students would provide useful information to those trying to support these students and may lead to a better understanding of women engineering students. 
In addition, there has been work on reasons influencing students' decision-making with regards to choice of major in the literature. Generally speaking, there is strong evidence showing that the choice of undergraduate major has a significant net impact on earnings. ${ }^{3}$ The framework of the determinants of student choice of undergraduate major field developed by Cebula and Lopes (1982) suggested that monetary variables (expected future earnings) are an important factor when selecting a major field of study. ${ }^{4}$

Fisher et al. (1997) explored the reasons why students choose computer science as a major and why they follow through on getting the degree. ${ }^{5}$ Fisher's findings indicate that while men are mostly motivated to continue with computer science due to their intrinsic interest, women have a broader range of motivational factors. ${ }^{5}$ In building on this literature, we are looking at what motivates students to study engineering in six different engineering majors. Our results are similar to Fisher's in our focus on gender differences and showing that what motivates women is different for women of different majors. These trends begin to suggest that changes may be needed in programs and curriculum to better support the different motivation patterns of men and women.

\section{Background on Instrument}

The goal of the Center for the Advancement of Engineering Education's Academic Pathways Study (APS) is to understand the engineering student learning experience. The online Academic Pathways of People Learning Engineering Survey (APPLES), was deployed in the Spring of 2008 to over 4000 undergraduate engineering students at 21 different institutions. The survey and took about 10 minutes to complete and participants were paid $\$ 4 .{ }^{6,7,8}$

The 21 APPLES institutions were selected to broadly represent American undergraduate engineering students. We used multiple criteria in sampling institutions, including Carnegie classification; student body composition by ethnicity, gender, and enrollment status; institution size; geographical location; type (public or private), and number of transfer students. ${ }^{6,7,8}$

At the core of the APPLES instrument are a set of variables that influence undergraduates' persistence in the engineering major, including motivation to study engineering. The survey probed six factors affecting motivation: financial, parental influence, social good, mentor influence, intrinsic psychological, and intrinsic behavioral. Table 1 summarizes these definitions. 


\begin{tabular}{|l|l|}
\hline $\begin{array}{l}\text { Motivational } \\
\text { Factor }\end{array}$ & Description \\
\hline Financial & $\begin{array}{l}\text { motivation to study engineering due to the belief that engineering will } \\
\text { provide a financially rewarding career }\end{array}$ \\
\hline $\begin{array}{l}\text { Parental } \\
\text { Influence }\end{array}$ & motivation to study engineering due to parental influences \\
\hline Social Good & $\begin{array}{l}\text { motivation to study engineering due to a belief that engineers improve the } \\
\text { welfare of society, 10 }\end{array}$ \\
\hline $\begin{array}{l}\text { Mentor } \\
\text { Influence }\end{array}$ & $\begin{array}{l}\text { motivation to study engineering due to the inspiration or encouragement of } \\
\text { a mentor either within the university or outside the university }\end{array}$ \\
\hline $\begin{array}{l}\text { Intrinsic } \\
\text { Psychological }\end{array}$ & $\begin{array}{l}\text { motivation to study engineering due to intrinsic psychological reasons } \\
\text { related to interest in the engineering field }\end{array}$ \\
\hline $\begin{array}{l}\text { Intrinsic } \\
\text { Behavioral }\end{array}$ & $\begin{array}{l}\text { motivation to study engineering due to intrinsic reasons that are } \\
\text { behavioral, practical, and hands-on in nature }\end{array}$ \\
\hline
\end{tabular}

Table 1. Motivational factors with what the construct was designed to measure.

\section{Methodology}

In APPLES, students reported their current or first choice of major in addition to their second choice or second major/minor. For this paper we limited our scope to the current or first choice of major so as to allow for each student to be counted only once in the cross-major comparisons.

Our analysis included only juniors and seniors. We believe these students were more likely than underclassmen to graduate in the major they selected (thereby minimizing responses from students who may later decide to transfer out of the major). Furthermore, we expect that juniors and seniors have completed more major-specific coursework resulting in responses that reflect a more complete picture of the specific major's engineering curriculum. We did not include $5^{\text {th }}$ year (or more) seniors in our analysis.

In order to determine the effects of collapsing men and women students of both junior and senior level standing into one group representing their engineering major, we first tested for statistically significant differences between these groups for students studying mechanical engineering. Using independent t-test comparisons, we chose to take a closer look at the similarities and differences within a major using the mechanical engineering students since we had the most data for this major. Table 2 shows the number and breakdown of mechanical engineering students in our data set.

\begin{tabular}{|l|r|r|r|}
\cline { 2 - 4 } \multicolumn{1}{c|}{} & Juniors & Seniors & Total \\
\hline Women & 54 & 52 & 106 \\
\hline Men & 194 & 195 & 389 \\
\hline Total & 248 & 247 & 495 \\
\hline
\end{tabular}

Table 2. Number of mechanical engineering students in APPLES data set by gender and academic standing.

Using independent t-tests, we compared these students by class standing and gender. Table 3 depicts these results. We found no statistically significant differences in motivational factors between mechanical engineering juniors and seniors either overall or when looking at only women or only men. We did, however, find that women and men in the major had statistically 
significantly different responses for intrinsic behavioral motivation $(\mathrm{p}<0.001)$, mentor influence on motivation $(\mathrm{p}<0.001)$, and parental influence on motivation $(\mathrm{p}<0.05)$.

\begin{tabular}{|l|l|r|l|l|l|l|l|l|r|}
\cline { 2 - 11 } \multicolumn{1}{c|}{} & \multicolumn{3}{c|}{ All } & \multicolumn{3}{c|}{ Jr } & \multicolumn{3}{c|}{ Sr } \\
\cline { 2 - 11 } \multicolumn{1}{c|}{} & sig. & \multicolumn{1}{l|}{ W } & M & sig. & W & M & sig. & W & M \\
\hline Financial & none & 67.1 & 64.4 & none & 66.7 & 63.7 & none & 67.5 & 65.1 \\
\hline Parental Influence & $*$ & 17 & 10.7 & $*$ & 19.4 & 10.8 & none & 14.4 & 10.6 \\
\hline Social Good & none & 77 & 75.7 & none & 77 & 75.2 & none & 77.1 & 76.2 \\
\hline Mentor Influence & $* * *$ & 49.4 & 34.9 & $* * *$ & 47.9 & 33.9 & $* * *$ & 51 & 35.9 \\
\hline $\begin{array}{l}\text { Intrinsic } \\
\text { Psychological }\end{array}$ & & & & & & & & & \\
\hline Intrinsic Behavioral & none & 81.4 & 82 & none & 79.7 & 81.5 & none & 83.2 & 82.5 \\
\hline
\end{tabular}

Table 3. Comparison of motivations to study engineering for mechanical engineering men and women of junior and senior standing. $* * * \mathrm{p}<0.001 ; * * \mathrm{p}<0.01 ; * \mathrm{p}<0.05$

Table 3 presents the means of the six motivational factors for mechanical engineering majors and the results of the independent t-tests by gender. There were no significant differences found between juniors and seniors. The means for each factor are presented on a normalized scale of 0 (low motivation) to 100 (high motivation).

We performed similar analyses of the other majors, separating men and women subjects due to these observed differences and gender oversampling. Since the responses of the juniors and seniors in mechanical engineering were similar and the statistical power that would be gained from increasing the number of respondents for the analyses, we collapsed the juniors and seniors within each major.

We selected six engineering majors for comparison: mechanical, electrical, chemical, industrial, aerospace and bioX. BioX engineering represents all biology-related engineering majors (e.g. biosystems engineering, biomechanical engineering, etc.) in the sample. We selected these six majors because of the broader picture they represent. These majors are offered at many institutions, and the APPLES data set for each of these six majors contains data from at least nine of the 21 APPLES schools. Table 4 shows the distribution of juniors and seniors by gender for each major. The juniors and seniors are combined throughout the rest of this analysis. The women and men are kept separate.

\begin{tabular}{|c|c|c|c|c|c|c|c|}
\hline & \multicolumn{3}{|c|}{ Number of Women } & \multicolumn{3}{|c|}{ Number of Men } & \\
\hline Major & Juniors & Seniors & Total & Juniors & Seniors & Total & TOTAL \\
\hline Aerospace & 8 & 4 & 12 & 41 & 34 & 75 & 87 \\
\hline Chemical & 41 & 19 & 60 & 30 & 12 & 42 & 102 \\
\hline Electrical & 24 & 32 & 56 & 107 & 113 & 220 & 276 \\
\hline Industrial & 48 & 21 & 69 & 39 & 30 & 69 & 138 \\
\hline Mechanical & 54 & 52 & 106 & 194 & 195 & 389 & 495 \\
\hline BioX & 23 & 28 & 51 & 34 & 20 & 54 & 105 \\
\hline
\end{tabular}

Table 4. Number of student responses by major, gender, and academic standing. 


\section{Independent T-tests}

We conducted independent t-tests for each of the other majors: electrical engineering, chemical engineering, industrial engineering, bioX engineering, and aerospace engineering. We compared the responses given by women to the responses given by men for each motivational factor. The results from these independent t-tests are displayed in Tables 5 thru 10 in the Results section; highlighted values indicate a statistically significant difference in responses between women and men.

\section{Paired T-tests}

We also conducted paired t-tests comparing the responses for each of the motivational factors. This allowed us to rank the motivational factors according to their means for each major and by gender. A different rank was given for a particular motivational factor when the paired t-tests indicated a statistically significant difference $(\mathrm{p}<0.001)$ between that motivational factor and any of the other similarly ranked factors. These results are also displayed in Tables 5 thru 10.

\section{Analysis of Variance}

We also conducted the analysis of variance test (ANOVA) to compare responses for each motivational factor by major. The Welch and Brown-Forsythe tests were used to determine which motivational factors had statistically significant differences. We chose to use these tests due to the differences in the sample sizes among majors. Table 4 shows the differences in sample sizes when comparing women of different majors or men of different majors.

For women, highly statistical differences $(\mathrm{p}<0.001)$ exist among majors for Intrinsic Behavioral Motivation, Intrinsic Psychological Motivation, and Financial Motivation. For men, there were statistical differences $(\mathrm{p}<0.001)$ for Intrinsic Psychological Motivation.

We then conducted a Dunnett's C multiple comparisons test to determine which majors were significantly different from each other. The average value for each major's response for each motivational factor is represented in Figures 1 and 2. Curved brackets indicate the significantly difference pairs according to the Dunnett's $\mathrm{C}$ test with significance at 0.001 or less.

\section{Results}

Our findings indicate there are significant differences between majors with respect to students' motivations to study engineering. These results are confounded by gender.

\section{Gender differences within a major}

In comparing men and women within a major, only mechanical engineers and industrial engineers had statistically significant differences at the $\mathrm{p}<0.001$ level (highlighted in Tables 5 and 8). Women in industrial engineering are less intrinsically behaviorally motivated than men. Women in mechanical engineering are also significantly less intrinsically behaviorally motivated and more motivated to study engineering due to mentor influence than men. The general 
agreement between women and men within a major, shown without highlighting in Tables 5 thru 10, indicates that men and women studying the same major are similarly motivated.

Ranking motivations within major by gender

Men in mechanical engineering, electrical engineering, and aerospace engineering had the same hierarchical ranking order of motivational factors: intrinsic behavioral, intrinsic psychological, social good, financial, and mentor influence followed by parental influence (Tables 5, 6, and 10). While men in chemical, industrial, and bioX engineering majors had some factors with the same rank, the order of the motivational factors did not change for students in these majors as some factors were grouped together (Tables 7, 8, and 10).

Women, on the other hand, had more variability in what factors were ranked highest in addition to fewer significant differences between motivational factors; as a result, many of the motivational factors were ranked at the same level. Chemical and industrial engineering female students ranked intrinsic behavioral motivation fourth out of six. The same factor was ranked number one for the other women students and all of the male engineering students.

Another notable result is that mentor influence and parental influence are ranked at or near the bottom for all the majors for men and women alike.

\begin{tabular}{|l|c|c|c|c|}
\cline { 2 - 5 } \multicolumn{1}{c|}{} & \multicolumn{3}{c|}{ Mechanical Engineering Students } \\
\cline { 2 - 5 } \multicolumn{1}{c|}{} & \multicolumn{2}{c|}{ Mean Value } & \multicolumn{2}{c|}{ Overall Rank } \\
\hline $\begin{array}{l}\text { Motivational } \\
\text { Factor }\end{array}$ & Men & Women & Men & Women \\
\hline Intrinsic Behavioral & 91.7 & 82.5 & 1 & 1 \\
\hline $\begin{array}{l}\text { Intrinsic } \\
\text { Psychological }\end{array}$ & 82 & 81.4 & 2 & 1 \\
\hline Social Good & 75.7 & 77 & 3 & 1 \\
\hline Financial & 64.4 & 67.1 & 4 & 4 \\
\hline Mentor Influence & 34.9 & 49.4 & 5 & 5 \\
\hline Parental Influence & 10.7 & 17 & 6 & 6 \\
\hline
\end{tabular}

Table 5. Mean values and ranking of motivational factors for upperclass men and women in mechanical engineering. Significant differences at the $\mathrm{p}<0.001$ level are highlighted.

\begin{tabular}{|l|c|c|c|c|}
\cline { 2 - 5 } \multicolumn{1}{c|}{} & \multicolumn{4}{c|}{ Electrical Engineering Students } \\
\cline { 2 - 5 } \multicolumn{1}{c|}{} & \multicolumn{2}{c|}{ Mean Value } & \multicolumn{2}{c|}{ Overall Rank } \\
\hline $\begin{array}{l}\text { Motivational } \\
\text { Factor }\end{array}$ & Men & Women & Men & Women \\
\hline Intrinsic Behavioral & 86.5 & 86.1 & 1 & 1 \\
\hline $\begin{array}{l}\text { Intrinsic } \\
\text { Psychological }\end{array}$ & 81.4 & 87.3 & 2 & 1 \\
\hline Social Good & 76.2 & 83.1 & 3 & 1 \\
\hline Financial & 66.1 & 72.6 & 4 & 4 \\
\hline Mentor Influence & 35.5 & 39 & 5 & 5 \\
\hline Parental Influence & 15.8 & 19.6 & 6 & 6 \\
\hline
\end{tabular}

Table 6. Mean values and ranking of motivational factors for upperclass men and women in electrical engineering. There were no significant differences between men and women. 


\begin{tabular}{|l|c|c|c|c|}
\cline { 2 - 5 } \multicolumn{1}{c|}{} & \multicolumn{4}{c|}{ Chemical Engineering Students } \\
\cline { 2 - 5 } \multicolumn{1}{c|}{} & \multicolumn{2}{c|}{ Mean Value } & \multicolumn{2}{c|}{ Overall Rank } \\
\hline $\begin{array}{l}\text { Motivational } \\
\text { Factor }\end{array}$ & Men & Women & Men & Women \\
\hline Intrinsic Behavioral & 75.4 & 63.9 & 1 & 4 \\
\hline $\begin{array}{l}\text { Intrinsic } \\
\text { Psychological }\end{array}$ & 81.3 & 75.9 & 1 & 1 \\
\hline Social Good & 81.2 & 76.9 & 1 & 1 \\
\hline Financial & 63.2 & 68.9 & 4 & 1 \\
\hline Mentor Influence & 30 & 43.3 & 5 & 5 \\
\hline Parental Influence & 12.7 & 18.1 & 5 & 6 \\
\hline
\end{tabular}

Table 7. Mean values and ranking of motivational factors for upperclass men and women in chemical engineering. There were no significant differences between men and women.

\begin{tabular}{|l|c|c|c|c|}
\cline { 2 - 5 } \multicolumn{1}{c|}{} & \multicolumn{4}{c|}{ Industrial Engineering Students } \\
\cline { 2 - 5 } \multicolumn{1}{c|}{} & \multicolumn{2}{c|}{ Mean Value } & \multicolumn{2}{c|}{ Overall Rank } \\
\hline $\begin{array}{l}\text { Motivational } \\
\text { Factor }\end{array}$ & Men & Women & Men & Women \\
\hline Intrinsic Behavioral & 72.6 & 55.3 & 1 & 4 \\
\hline $\begin{array}{l}\text { Intrinsic } \\
\text { Psychological }\end{array}$ & 73.6 & 65 & 1 & 1 \\
\hline Social Good & 72.2 & 68.9 & 1 & 1 \\
\hline Financial & 71.2 & 73.3 & 1 & 1 \\
\hline Mentor Influence & 37.2 & 34.5 & 5 & 5 \\
\hline Parental Influence & 13.9 & 23.8 & 6 & 5 \\
\hline
\end{tabular}

Table 8. Mean values and ranking of motivational factors for upperclass men and women in industrial engineering. Significant differences at the $\mathrm{p}<0.001$ level are highlighted.

\begin{tabular}{|l|c|c|c|c|}
\cline { 2 - 5 } \multicolumn{1}{c|}{} & \multicolumn{4}{c|}{ BioX Engineering Students } \\
\cline { 2 - 5 } \multicolumn{1}{c|}{} & \multicolumn{2}{c|}{ Mean Value } & \multicolumn{2}{c|}{ Overall Rank } \\
\hline $\begin{array}{l}\text { Motivational } \\
\text { Factor }\end{array}$ & Men & Women & Men & Women \\
\hline Intrinsic Behavioral & 81.2 & 72.2 & 1 & 1 \\
\hline Intrinsic & & & & \\
Psychological & 78 & 76.7 & 1 & 1 \\
\hline Social Good & 75.3 & 77.1 & 1 & 1 \\
\hline Financial & 59.5 & 51.9 & 4 & 4 \\
\hline Mentor Influence & 30.2 & 36.2 & 5 & 4 \\
\hline Parental Influence & 18.8 & 17.3 & 5 & 6 \\
\hline
\end{tabular}

Table 9. Mean values and ranking of motivational factors for upperclass men and women in bioX engineering. There were no significant differences between men and women. 


\begin{tabular}{|l|c|c|c|c|}
\cline { 2 - 5 } \multicolumn{1}{c|}{} & \multicolumn{4}{c|}{ Aerospace Engineering Students } \\
\cline { 2 - 5 } \multicolumn{1}{c|}{} & \multicolumn{2}{c|}{ Mean Value } & \multicolumn{2}{c|}{ Overall Rank } \\
\hline $\begin{array}{l}\text { Motivational } \\
\text { Factor }\end{array}$ & Men & Women & Men & Women \\
\hline Intrinsic Behavioral & 90.9 & 86.1 & 1 & 1 \\
\hline $\begin{array}{l}\text { Intrinsic } \\
\text { Psychological }\end{array}$ & 81.4 & 90.7 & 2 & 1 \\
\hline Social Good & 72.5 & 83.3 & 3 & 1 \\
\hline Financial & 62 & 50 & 3 & 4 \\
\hline Mentor Influence & 35.3 & 57.6 & 5 & 4 \\
\hline Parental Influence & 12.2 & 4.1 & 6 & 6 \\
\hline
\end{tabular}

Table 10. Mean values and ranking of motivational factors for upperclass men and women in aerospace engineering. There were no significant differences between men and women.

\section{Discussion}

Male engineers appear to be motivated similarly across the different engineering majors except for intrinsic behavioral motivation as seen on Figure 1. For intrinsic behavioral motivation, there is significant difference $(\mathrm{p}<0.001)$ between mechanical engineering students and industrial engineering students and between aerospace engineering students and industrial engineering students. Further investigation into the curriculum for each major may indicate a link between opportunities for hands-on building within an engineering major curriculum and intrinsic behavioral motivation. 


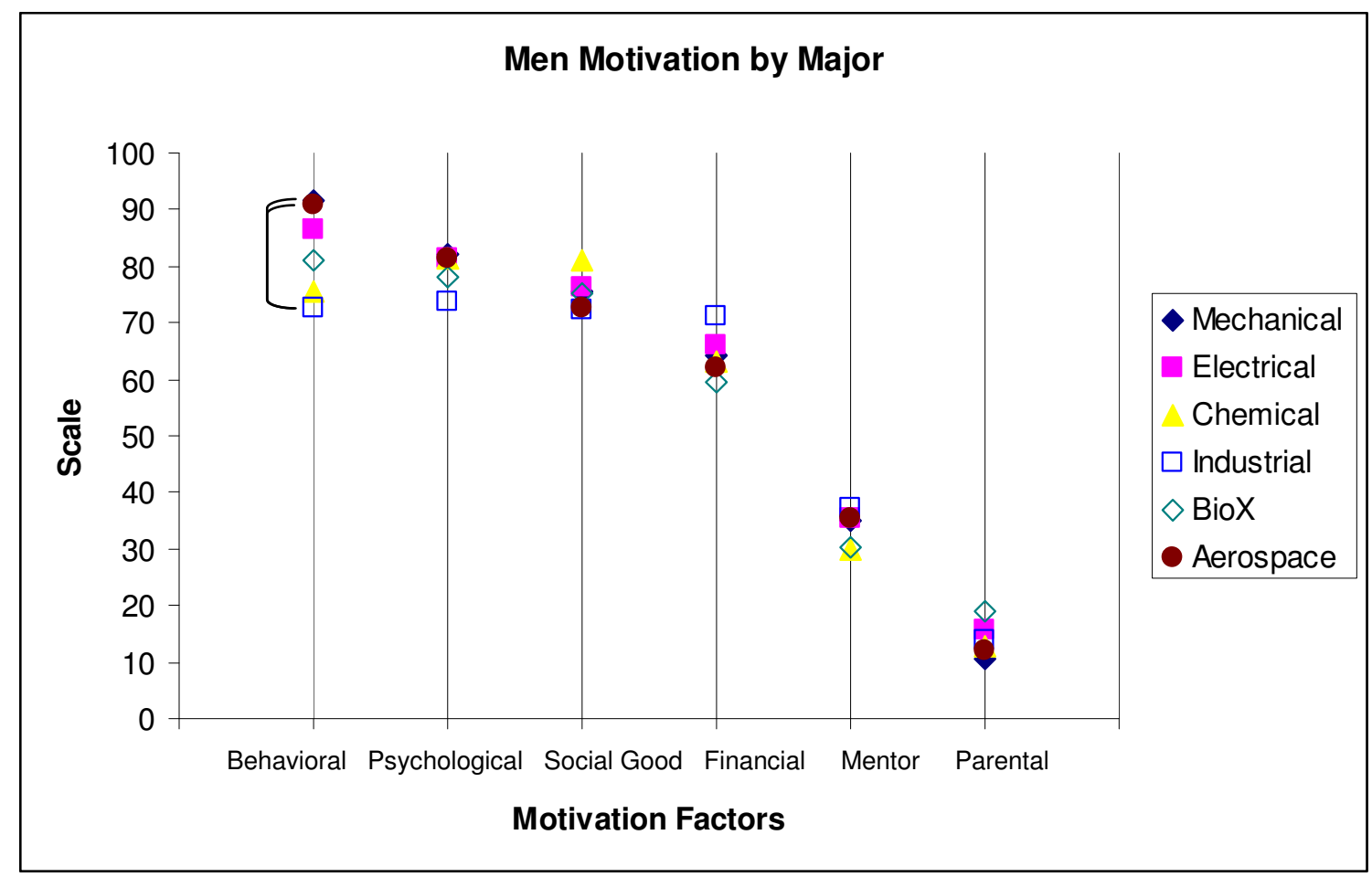

Figure 1. Men's mean level of motivation by engineering major for each motivational factor. Each motivational factor is presented on a normalized scale of 0-100. Significant differences $(\mathrm{p}<0.001)$ between pairs are indicated by curved braces.

Motivation to study engineering for women is different from men and different among majors. In Figure 2, for women, the means for each major are spread over a larger range than they are for men as seen in Figure 1. This range is statistically significant $(\mathrm{p}<0.001)$ for intrinsic behavioral, intrinsic psychological, and financial motivational factors. The level of intrinsic behavioral motivation to study engineering is significantly different $(\mathrm{p}<0.001)$ between students majoring in industrial engineering and mechanical engineering, industrial engineering and electrical engineering, and chemical engineering and electrical engineering. The level of intrinsic psychological motivation to study engineering is also significantly different between those majoring in industrial engineering and electrical engineering and those majoring in industrial engineering and mechanical engineering. Students' level of financial motivation differs between industrial engineering students and bioX engineering majors. 


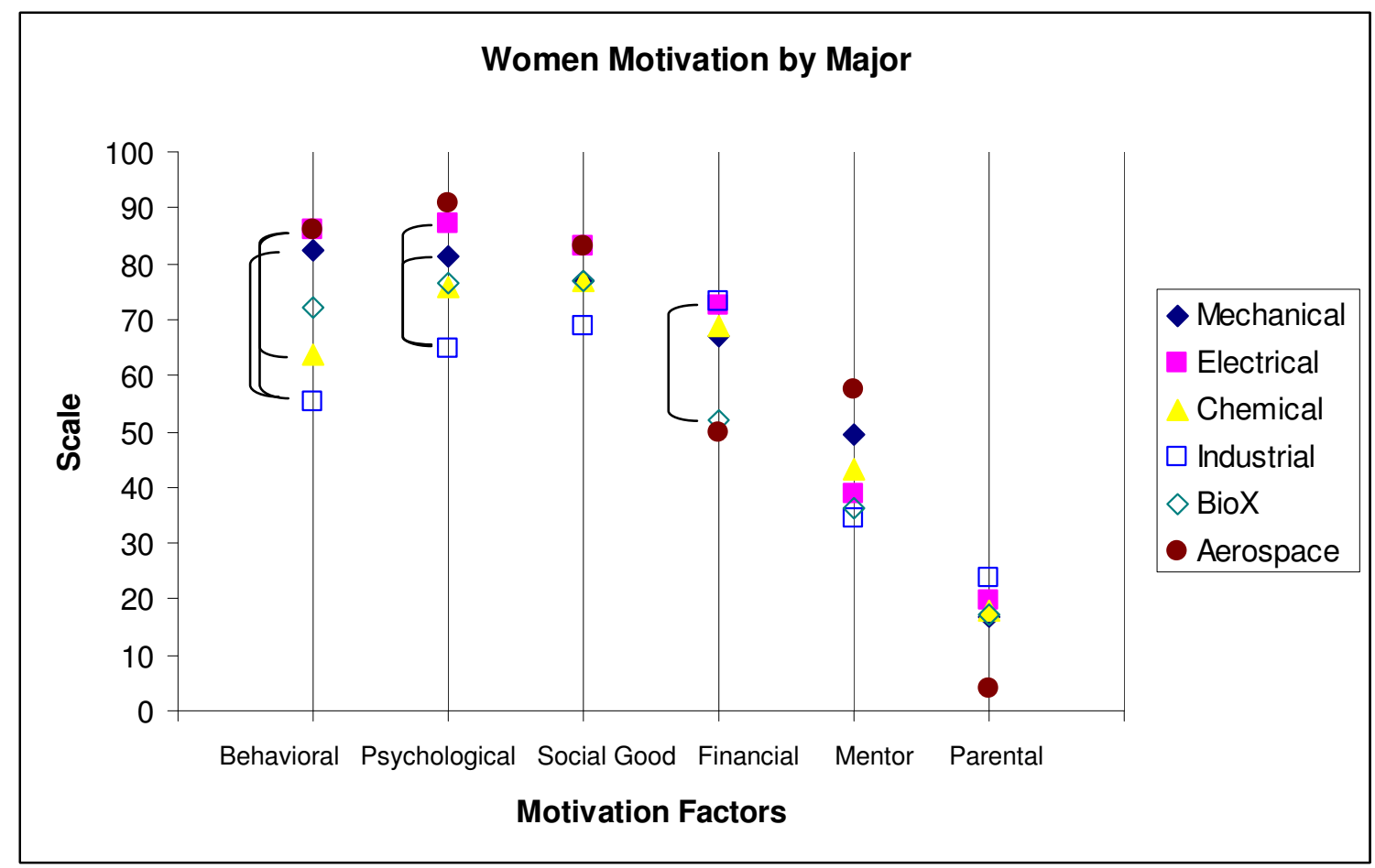

Figure 2. Women's mean level of motivation by engineering major for each motivational factor. Each motivational factor is presented on a normalized scale of 0-100. Significant differences $(\mathrm{p}<0.001)$ between pairs are indicated by curved braces.

Most of the majors had high levels of motivation for each of the motivational factors considered, yet industrial engineering women had much lower levels for each of the motivational factors. We are not claiming that these women are less motivated to study engineering, although that may be one explanation. There are also other motivational factors that we did not inquire about in the APPLES instrument. Some possibilities for additional motivational factors could include: a "coolness" factor to the major, flexibility of the degree plan and/or post-graduation plans, prestige of a degree, and interactions with peers.

\section{Conclusions}

Using data from the Academic Pathways of People Learning Engineering Survey (APPLES), we sought a better understanding of undergraduate engineering students' motivations relative to their majors.

In terms of gender, men and women are for the most part similar in their motivations to study engineering in the six majors analyzed. We found no statistically significant differences $(\mathrm{p}<0.001)$ between women and men's levels of motivation in the six motivational factors that were explored for electrical engineering students, chemical engineering students, aerospace engineering students, and bioX engineering students. In addition, behavioral motivation to study engineering ranks more highly than other motivational factors for men while women have a range of motivational factors that are ranked more equally. The level of motivation that women feel from intrinsic behavioral motivation, intrinsic psychological motivation, and financial motivation varies by major. This shows us that we cannot simply group all students together 
when describing engineering students especially women, whose motivational factors vary by major.

The work presented here may allow for changes to be made in support programs and engineering curriculum so that they better meet the needs of women and men in each of the engineering disciplines by addressing the motivational factors that are specific to each group.

\section{Acknowledgements}

The Academic Pathways Study (APS) is supported by the National Science Foundation under Grant No. ESI-0227558 which funds the Center for the Advancement of Engineering Education (CAEE). CAEE is a collaboration of five partner universities. We would like to thank Micah Lande and George Toye for all of their support from helping to develop the research question to encouraging us to think more deeply. One of the authors (SP) received support from the NSF Graduate Research Fellowship and the Stanford Graduate Fellowship.

\section{References}

1. S. Sheppard, Atman, C., Stevens, R., Fleming, F., Streveler, R., Adams, R., \& Barker, T. (2004). Studying the Engineering Student Experience: Design of a Longitudinal Study. In Proceedings of the American Society for Engineering Education Annual Conference, Salt Lake City, UT.

2. $\quad$ Clark, M., Sheppard, S., Atman, C., Fleming, L., Miller, R., Stevens, R., Streveler, R., \& Smith, K. (2008) Academic Pathways Study: Processes and Realities. In Proceedings of the American Society for Engineering Education Annual Conference, Pittsburgh, PA.

3. Pascarella, E.T. and P.T. Terenzini. 2005. How college affects students (Volume 2): A third decade of research. San Francisco, CA: Jossey-Bass

4. Cebula, R.J., \& Lopes, J. (1982). Determinants of student choice of undergraduate major field. American Educational Research Journal, 19(2), 303-312.

5. Fisher, A., J. Margolis, and F. Miller, Undergraduate women in computer science: experience, motivation and culture. SIGCSE Bull., 1997. 29(1): p. 106-110.

6. Donaldson, K. and Sheppard, S. (2007) A Snapshot of American Undergraduate Engineering Institutions: National Sampling for the Academic Pathways of People Learning Engineering Survey (APPLES). CAEE Technical Report Series: CAEE-TR-08-05. Seattle, WA: Center for the Advancement of Engineering Education.

7. Donaldson, K., Chen, H.L., Toye, G., Clark, M., \& Sheppard, S. (2007). Targeting Undergraduate Students for Surveys: Lessons from the Academic Pathways of People Learning Engineering Survey (APPLES). In Proceedings of the Frontiers in Education Annual Conference, Milwaukee, WI.

8. Donaldson, K., Chen, H.L., Toye, G., Clark, M., \& Sheppard, S. (2008). Scaling Up: Taking the Academic Pathways of People Learning Engineering Survey (APPLES) National. In Proceedings of the Frontiers in Education Annual Conference, Saratoga Springs, NY. 
9. $\quad$ Eris O., Chen, H.L., Bailey, T., Engerman, K., Loshbaugh, H.G., Griffin, A., Lichtenstein, G., Cole, A. (2005). Development of the Persistence in Engineering (PIE) survey instrument. In Proceedings of the American Society for Engineering Education Annual Conference, Portland, OR.

10. Eris O., Chachra D., Chen H.L., Rosca C., Ludlow L., Sheppard S.D., Donaldson K. (2007). A preliminary analysis of correlates of engineering persistence: Results from a longitudinal study. In Proceedings of the American Society for Engineering Education Annual Conference, Honolulu, HI.

11. Chen, H., K. Donaldson, O. Eris, D. Chachra, G. Lichtenstein, S. Sheppard, G. Toye. (2008) From PIE to APPLES: The Evolution of a Survey Instrument to Explore Engineering Student Pathways. in American Society for Engineering Education Annual Conference. Pittsburg, PA. 